\title{
OS PRIMEIROS TEMPOS DA PSICANÁLISE NO BRASIL E AS TESES PANSEXUALISTAS NA EDUCAÇÃO
}

C. Lucia Montechi Valladares de Oliveira

Socióloga, doutora em História pela Universidade de ParisVII; pós-doutoranda da Fapesp no Laboratório de Psicopatologia Fundamental do Programade Estudos Pós-Graduados em Psicologia Clínica, PUC-SP.
RESUMO: Analisam-se as primeiras estratégias de introdução da psicanálise no Brasil pela via pedagógica. Procura-se mostrar como 0 debate europeu em torno da temática do pansexualismo freudiano foi apropriado pelos primeiros comentadores dessa doutrina no país e quais os seus efeitos na difusão desse saber.

Palavras-chave: História, psicanálise, pedagogia, pansexualismo, estratégias.

ABSTRACT: The early days of psychoanalysis in Brazil and the pansexualist thesis in education. This paper analyses the early strategies to introduce psychoanalysis in Brazil through pedagogy. It tries to demonstrate how the European debate on the Freudian pansexualist doctrine was suitable to its early defenders, and what were the consequences of the propagation of this theory.

Keywords: History, psychoanalysis, pedagogy, pansexualism, strategies.

Gegundo a historiografia, no Brasil, as primeiras referências às teses freudianas ocorrem no meio psiquiátrico ca rioca. A primazia dessa difusão cabe a Juliano Moreira, fundador da psiquiatria moderna no país, que em 1914 apresenta um trabalho sobre o tema na Sociedade Brasileira de Psiquiatria, Neurologia e Medicina Legal. ${ }^{1}$ Desde então, além de co-

\footnotetext{
${ }^{1}$ Segundo o psiquiatra e psi canalista Júlio Pires Porto-Carrero, o primeiro historiador da psicanálise no país, os registros mais remotos sobre a difusão desta doutrina no Brasil datam de 1899, quando o jovem médico baiano Juliano Moreira, na ocasião completando sua formação com Emile Kraepelin na Alemanha, comenta na Faculdade de Medicina da Bahia as teses de Freud. Após esse comentário, contemporâneo à publicação de A interpretação dos sonhos, mas do qual pouco se sabe sobre a sua veracidade, é somente a partir de 1914 que as teses freudianas começam de fato a circular no Brasil de forma mais sistemática (PORTO-CARRERO, 1928a/ 1929, p. 11-25).
} 
mentar e eventualmente aplicar algumas técnicas em sua clínica, juntamente com outras personalidades da psiquiatria local, ele procura estimular seus discípulos ao estudo da psicanálise. Resultado: em 1915, o aluno de Antonio Austregésilo, Genserico Aragão de Souza Pinto, publica sua tese de medicina intitulada, Da Psychanalyse a sexualidade das neuroses. ${ }^{2}$ Mas, ao longo desse período a personalidade carioca mais motivada pela psicanálise é sem dúvida Júlio Pires Porto-Carrero. Adepto de primeira hora, a partir de 1919 ele se dedica ao estudo do alemão, como dizia, "para ler Freud no original", iniciando sua clínica em 1923 no seio da Liga Brasileira de Higiene Mental (LBHM).

Ainda que não seja praticada de forma sistemática, nesses primeiros tempos, a temática freudiana ocupa um lugar particular no meio psiquiátrico carioca, sendo comentada e discutida pelos principais expoentes desse saber e merecendo as mais variadas interpretações, apreciações e utilizações que oscilam entre a simpatia, a adesão, mas também a recriminação, não raro pautadas na idéia de pansexualismo, bastante em voga na Europa. A psicanálise se apresenta menos como uma alternativa à psiquiatria puramente organicista, classificatória e incapaz de apresentar uma solução ao tratamento das psicopatias, que como um método complementar às diferentes técnicas de cura existentes.

Já em São Paulo, o debate tem início um pouco mais tarde, em 1920, com a publicação do livro 0 pansexualismo na doutrina de Freud, de autoria de Franco da Rocha. Mas, apesar de ter sido lançada pelo principal expoente da psiquiatra local, o "Pinel paulista" como era chamado carinhosamente pelos seus discípulos, não é pela via psiquiátrica que a psicanálise vai se expandir nessa cidade, mas graças a uma grande difusão no meio intelectual e sobretudo literário através dos modernistas. Leitores de Freud em francês, ainda que façam uma leitura bastante particular, irreverente, e diferente da dos escritores franceses, sobretudo aqueles ligados ao movimento surrealista, suas interpretações são profundamente marcadas pelas teses originárias da psicologia francesa, em particular as deThéodule Ribot. 0 mais próximo dessa corrente é Mário deAndrade, cuja influência já se verifica em seu poema "Paulicéia desvairada", escrito em dezembro de 1920 e publicado em 1922. De uma maneira geral, os modernistas tentam, a um só tempo, acomodar as teses freudianas à problemática inerente à produção literária deles e à reflexão que fazem sobre a questão da identidade nacional.

U ma vez lançada, ao longo do decênio 1920 a psicanálise vai rapidamente se tornar objeto de comentários e análises da parte dos mais importantes inte-

${ }^{2}$ Optamos por conservar as citações na ortografia da época. 
lectuais dessas duas cidades. ${ }^{3}$ M édicos, psiquiatras, cronistas sociais, pedagogos, a favor ou contra, vão abordar a temática freudiana pela idéia de pansexualismo deslocando esse saber do quadro clínico para o social. Eles se servem do termo tanto pelo viés moralista e/ ou nacional, de resistência à psicanálise, quanto pelo seu aspecto inovador, moderno, para valorizar os méritos da doutrina e de sua base psicológica, mas igualmente no seu sentido filosófico, como sistema explicativo do social.

Essa maneira de se apropriar das teses freudianas não tem nada de inócua. Isto porque, de um lado, as idéias psicanalíticas chegam ao Brasil no momento em que a psicanálise ganha projeção internacional ao mesmo tempo que é alvo de críticas severas, sendo tachada principalmente de teoria pansexualista. ${ }^{4}$ De outro, porque, no plano local, a temática pansexualista encontra ecos na reflexão dos intelectuais brasileiros nos desejos de contribuir para a construção do Estado nacional. Vale lembrar, entre outras coisas, a importância atribuída à problemática sexual sobretudo nas campanhas higienistas, que sugerem um modelo de disciplinarização e controle das normas e práticas sociais. Alias, é desse movimento que a psicanálise emerge, assinala Russo, como esforço civilizador-educativo (RUSSO, 1997).

No presente artigo, procuraremos mostrar como o debate europeu em torno do pansexualismo, e em particular o que se trava na França nesse primeiro momento de recepção da psicanálise no Brasil, influenciou o meio intelectual brasileiro e quais as suas repercussões. Ao mesmo tempo, procuraremos precisar as referências que norteiam a reflexão de al guns dos primeiros comentadores do freudismo.

\footnotetext{
${ }^{3}$ Com exceção de algumas manifestações isoladas, resultado do interesse de celebridades da psiquiatria brasileira durante os primeiros decênios do século XX, a difusão da psicanálise fica de fato restrita a esses dois centros urbanos. A título de exemplo, podemos citar as iniciativas dos psiquiatras gaúchos Martim Gomes e Dyonélio Machado, no Rio Grande do Sul (GAGEIRO,2001), os escritos de Arthur Ramos, em Salvador; além de uma certa simpatia pela temática psicológica da parte de U lisses Pernambucano, em Recife, ou ainda pela via literária, em Belo Horizonte, através do médico lago Pimentel, que começou a traduzir Cinco lições de psicanálise numa publicação literária de vida efêmera, A Revista, em 1925.

${ }^{4} 0$ termo, inventado pelo psiquiatra suíço Eugen Bleuler, foi utilizado para designar de forma pejorativa a doutrina freudiana, principalmente na Europa. Como lembram Elisabeth Roudinesco e Michel Plon, ainda que lançadas a partir da publicação de Trêsensai os sobrea teoria da sexual idade, em 1905, as acusações de pansexual ismo eclodem verdadeiramente entre 1910 e 1913, momento em que a doutrina adquire reconhecimento internacional: o freudismo, lembram os autores, "começa a ser tratado, em diversas partes do mundo, como uma'obscenidade', uma'pornografia', uma'coisa sexual', ou ainda uma' ciência boche' ". Para eles, as resi stências à psicanálise, em nome de uma moral calvinista, como foi o caso da escola de Zurique, ou de "naturezanacional" como na França, em nome de uma latinidade, de um espírito cartesi ano que historicamente se opõem ao pensamento germânico, romântico e supostamente obscurantista, foram "o sintoma evidente da sua projeção" (ROUDINESCO, PLON, 1997, p. 1.077).
} 
Como assinala Roudinesco, na França, onde a primeira fase de introdução da psicanálise ocorre entre 1895 e 1914, o interesse pela psicanálise se manifesta de forma ambivalente, "entre a resistência e a fascinação" (ROUDINESCO, 1994 , p. 227). Os intelectuais franceses, continua a autora, "ora utilizam a Suíça para introduzir a doutrina vienense, ora valorizam o 'crivo latino' para fabricar uma teoria freudiana conforme os seus ideais" (ROUDINESCO, 1994, p. 224).

Ora, essa mesma oscilação, entre a resistência e a fascinação, encontramos nos discursos dos primeiros comentadores do freudismo no Brasil, não por acaso marcados por uma filiação intelectual à França. No meio médico brasileiro, por exemplo, essa aproximação passa por uma tradição de leitura dos trabalhos de Charcot, Janet, Babinski, Déjerine, assim como de Bernheim, e pela forma como eles absorvem essas diferentes teorias, por vezes antagônicas para, partindo delas, formularem as suas próprias versões. Vejamos então algumas considerações que norteiam o posicionamento desses primeiros comentadores das obras freudianas.

Entre os mais célebres psiquiatras interessados por essa temática ainda que emitindo reservas, vale citar Henrique Belford Roxo. Para esse autor o fundamento "anatomo-clínico" da doença mental reside no "vago-sympatico" e em "lesões dos corpos optico-estrados"; mas atento aos ensinamentos de Babinski, ele atribui um grande valor às emoções, sobretudo na constituição da histeria e ao tratamento pela sugestão. Por outro lado, apesar de suas reservas à doutrina, ele faz sempre questão de realçar os "serviços relevantíssimos" que esta presta à psiquiatria (ROXO, 1934a, p. 6). Razão pela qual, em 1918, ele a introduz seu curso de psiquiatria na Faculdade de M edicina do Rio de Janeiro. Em seu Manual de Psychiatria, publicado em 1921, ele vai mais longe. Situa a psicanálise no quadro da evolução do saber psiquiátrico e destina um capítulo inteiro ao fundador da doutrina, aliás o único autor a merecer tamanho destaque no livro (ROXO, 1921, p. 18). É interessante notar que, tanto no Manual quanto em estudos posteriores, Roxo insiste em salientar que "há uma relação muito estreita entre a sexualidade e a demência precoce", acrescentando: "Quando esta se não segue a um processo toxi-infeccioso ou a um distúrbio endócrino e vem em conseqüência de um pensamento obsessivo, torturante, é, na quasi unanimidade dos casos, a questão sexual que predomina" (ROXO, 1934b, p. 31). Mas, ainda que considerando que "a questão do inconsciente é de primeira importância" assim como "a doutrina de Freud" para a definição da doença mental, ele temporiza. Ou seja, se por um lado reconhece a dimensão sexual na explicação da etiologia da histeria, por outro, considera "verdadeiramente um absurdo" atribuir à sexualidade causalidade única (ROXO, 1921, p. 650). 0 que não impede que utilize algumas das técnicas psicanalíticas em 
sua clínica adequando-as aos diversos tratamentos, inclusive com pacientes diagnosticados como esquizofrênicos.

"Dos processos para fazer a psycho-analyse, parece-me ser a analyse dos sonhos a menos aproveitável no caso [de paciente esquizofrênico]. Tenho applicado muito a observação das associações de idéias livres ou espontaneas e a interpretação das distracções ou descuidos nos factos da vida diária." (ROXO, 1934b, p. 32)

U ma outra personalidade interessada pela temática freudiana é Antonio Austregésilo. Médico conceituado, professor de clínica neurológica da Faculdade de Medicina do Rio de Janeiro e autor de numerosos trabalhos e artigos de vulgarização da medicina, Austregésilo é leitor tanto de Déjerine, quanto do fundador da Escola de Nancy, Bernheim, mas sobretudo do discípulo preferido de Charcot, Babinski, com quem partilha também muitas das posições. Para esse defensor de uma psicoterapia de base educativa, as psiconeuroses possuem uma base moral e é dever do médico educar os pacientes (AUSTREGÉSILO, 1917, p. 172). Aliás, é através dessa "base moral" que ele reconhece que "a esfera genital ocupa um lugar importante na constituição das neuropatias" (Idem, $1917 / 1946$, p. 92). Por outro lado, convencido de que todo trabal ho clínico consiste em "destruir as idéias fixas", ou "desviar" a atenção do paciente, ele considera "exageradas" as generalizações de Freud que explica "tudo pelo sexual", e combate a sua aplicação.

"O método curativo da psicanálise de Freud tem sido aplicado, entre nós, na clientela privada. Prefiro porém, os meios gerais de análise mental, os métodos psicoterápicos, para apagar as idéias sentimentais ou as emoções mórbidas que cansam ou irritam a alma do padecente." (AUSTREGÉSILO, 1917/ 1946, p. 92)

É interessante notar que esse olhar sobre a psicanálise pela vertente francesa é bastante freqüente nessa época. Aliás, Medeiros de Albuquerque, o qual, com razão, vê nessa filiação um obstáculo à difusão da psicanálise, não hesita em chamar a atenção: "Nós só recebemos idéias científicas por intermédio da França" (MEDEIROS DE ALBU QUERQUE, 1922, p. 103). E a Franco da Rocha de completar no prefácio do seu Pansexualismo na doutrina de Freud, afirmando que seu objetivo com o livro é transmitir uma doutrina da qual fala-se muito, mas que poucos a conhecem, entre outras, em razão da sua língua de origem, o alemão, pouco difundido no Brasil (FRANCO DA ROCHA, 1920, p. III).

$O$ fato é que nessa época, muitos dos posicionamentos sobre a psicanálise são referenciados nos trabalhos de Régis e Hesnard, autores do primeiro livro sobre a psicanálise na França, La psychoanalyse des névroses et des psychoses, cujo 
essencial consiste justamente em rejeitar a doutrina germânica em favor de uma latinização da psicanálise. Aliás, esse livro foi traduzido e publicado no Brasil em 1923, ao passo que a primeira tradução de um texto de Freud em português data de 1931.

Afrânio Peixoto, por exemplo, é um dos que em 1918 introduz as teses de Freud em seu curso de psiquiatria médico-legal na Faculdade de Medicina do Rio de Janeiro através desses autores. ${ }^{5}$ Inclui-se também nessa corrente o próprio Franco da Rocha, ainda que para ele o pansexualismo, longe de constituir uma objeção, é a expressão mesma da doutrina.

"A crítica de Régis e Hesnard, uma das mais sérias e, como dissemos, dominada por um espírito scientífico, essa é de molde a fazer aceitar o pansexualismo de preferência a rejeitá-lo. 0 ataque é frouxo e só pode impressionar a quem não tenha prática do estudo das nevroses e psiconevroses, isto é, a quem não tenha convicções assentadas em longa experiência." (FRANCO DA ROCHA, 1920, p. 179)

Mas, se a problemática sexual mobiliza a atenção dos médicos, para quem o hereditarismo não é suficiente para explicar a etiologia das doenças nervosas, não é apenas porque a psicanálise vem preencher uma deficiência nos conhecimentos que Franco da Rocha chama de "processos biológicos que constituem a natureza da sexualidade" (FRANCO DA ROCHA, 1920, p. 58). Mas também porque, como já mencionamos antes, os seus pressupostos se acomodam ao projeto mais amplo de construção da nação brasileira. E é justamente nesse aspecto que a problemática pansexualista ganha coloração local e, em parte, se diferencia do debate europeu.

Vale lembrar que, nessa época, o discurso médico brasileiro, de maneira predominante, se pauta na concepção higienista, baseada na idéia de desvio físico e psíquico e centrada nas noções de prevenção e educação. Essa geração de médicos tem como missão o estabelecimento de medidas profiláticas com vistas a corrigir os "defeitos", garantir uma "procriação sadia" e formar uma "boa geração" de brasileiros, capaz de "enobrecer" o futuro da nação. E muitos são os adeptos das teses freudianas que vêem nessa proposição médica, que investe na esfera da vida privada da família, um lugar nobre para a tal psicanálise pansexualista pois para eles ela traz uma contribuição de valor científico, portanto positivo, que pode ser traduzido em um programa preventivo de educação sexual endereçado não só aos pais mas também às crianças e aos educa-

\footnotetext{
${ }^{5}$ Como assinalajane Russo, Afrânio Peixoto é representativo do modo como a grande maioria dos médicos se relacionava com a teoria freudiana, divulgando-a em seus escritos sem contudo adotála em suas clínicas (RUSSO, 1998).
} 
dores. Para ser mais precisa, eles vêem nessa concepção ao mesmo tempo sociológica e pedagógica da Saúde Mental uma aproxi mação com a pedagogia pel os pressupostos psicanalíticos. Alguns vão mesmo fazer dessa via a primeira estratégia de implantação da psicanálise no Brasil. E com isso amargar o primeiro fracasso dessa disciplina no país. Vejamos então como ocorre essa aproximação com o movimento pedagógico e posterior rejeição.

\section{A PSICANÁUSE NA EDUCAÇÃO, UMA ESTRATÉGIA}

Como é sabido, durante esse período o problema da educação nacional ocupa um lugar privilegiado entre as prioridades da administração republicana, mobilizando os mais importantes intelectuais do país que, seguindo a ótica dos médicos, consideram a "ignorância do povo brasileiro" como um das mais graves "doenças sociais" e uma das causas do "atraso" dessa sociedade com relação ao mundo "civilizado", para utilizarmos as expressões da época. No plano ideológico, o movimento pedagógico se encontra polarizado em torno de duas correntes: de um lado, a dos reformadores que lutam por uma escola laica, gratuita e para todos e, de outro, a dos grupos católicos que vêem na intervenção do Estado uma ameaça ao monopólio deles e, no ensino laico, uma ofensa aos princípios da educação católica (ROMANELLI, 1978, p. 130). A primeira corrente ganha corpo a partir de 1924, quando é fundada no Rio de Janeiro a Associação Brasileira de Educação ( $A B E$ ), órgão que reúne os educadores brasileiros defensores de idéias renovadoras, em torno de um projeto de lei para a Educação nacional e que dá origem ao Manifesto dos Pioneros da Escola Nova, em 1932.

Durante essa época, lembra Romanelli, o movimento renovador, ainda que acumulando diversas experiências, é suficientemente heterogêneo no plano teórico para comportar sem objetividade as mais diferentes doutrinas (ROMANELLI, 1978, p. 144). E entre elas figuram as teses freudianas, recentemente chegadas ao Brasil. Isso porque essa doutrina que dá a palavra à criança e que acentua as individualidades parece se adaptar de forma funcional aos pressupostos da nova pedagogia.

Mas, enquanto no seio daABE, os pedagogos progressistas, em meio a tantas outras proposições que circulam, discutem sobre a possibilidade de uma aproximação com a psicanálise, os primeiros psicanalistas brasileiros tomam a dianteira e lançam o debate. 0 mais motivado é, sem dúvida, o carioca Júlio Pires Porto-Carrero, "um fanático da psicanálise", como ele mesmo se nomeia e também o primeiro a partir em cruzada:

"Dos nossos esforços reunidos, possa derivar um Brasil melhor - eis o nosso ideal; não é tudo: que o Brasil futuro, maior pela instrução, celebre os nossos esforços eis o que nos impõe, tyrannico, o inconsciente." (PORTO-CARRERO, 1927a/ 1929, p. 62) 
Paralelamente à sua prática no hospital psiquiátrico ao lado de Juliano Moreira e no seio da LBHM, onde funda a primeira clínica psicanalítica no Brasil, PortoCarrero não mede esforços para situar a importância e o lugar que essa doutrina ocupa na prática pedagógica: ${ }^{6}$

"Dada a profunda influência da sexualidade na formação e operação da psyche infantil, não é justo que a educação se furte ao lado sexual da vida e repila, si mplesmente, como immoraes, as manifestações e os conhecimentos sexuais. Urge fazer a educação sexual." (PORTO-CARRERO, 1927b/ 1929, p. 58-59)

A proposição, endereçada aos pais, professores e às crianças, tem por objetivo formular aquilo que ele vai chamar de "as bases da educação moral do brasileiro" (1928b/ 1929), e é norteada por princípios racionais ditados pela psicanálise e em particular pelos ensinamentos extraídos de Totem e tabu sobre a religião, como reação ao misticismo e ao sentimento religioso (PORTOCARRERO, 1927b/ 1929). Partindo desse pressuposto, ele combate ao mesmo tempo a educação tradicional, muito repressiva, e a educação excessivamente permissiva, propondo uma solução intermediária.

Nessa perspectiva, concordamos com a tese de Russo quando afirma que esses primeiros adeptos vêem a doutrina como uma "teoria ampliada da sexualidade humana", que permite, entre outras, a proposta de um agenciamento e de um controle racional e civilizador da sexualidade, através de um discurso moralizador e de disciplinarização, mas que não preconiza uma ruptura com os comportamentos moralmente recomendados. 0 que é proposto, segundo Russo, é uma espécie de "contra-moral laica", que para ela é menos hipócrita e mais rigorosa em matéria de verdade científica (RUSSO, 1997, p. 14-15).

Mais ainda: fica claro que neste debate com os pedagogos, esse leitor de Freud na língua original não só não ignora os modelos psicológicos de classificação da personalidade, mas explicita sua proposição em oposição, entre outros, a Claparède e a Binet. Para Porto-Carrero, a contribuição da psicologia clássica, que nessa época exerce grande influência em diversos pedagogos brasileiros, não é suficiente para esclarecer os professores e os pais sobre os conflitos emocionais de natureza sexual que estão na origem das neuroses.

\footnotetext{
${ }^{6}$ Além do meio pedagógico, Porto-Carrero faz conferências e também atua em diversos outros meios intelectualizados, mas também em associações e sindicatos operários. Igualmente, ele dá entrevistas na imprensa e escreve artigos para publicações especializadas nas quais explica as técnicas psicanalíticas a partir de curas pelo método da associação de idéias. Incansável, ele se desloca para diversos cantos do país para exaltar o val or desse método preventivo e profilático. U ma boa parte dessas conferências e artigos está reunida em um livro publicado em 1929 sob o título Ensaios de psychanalyse, e está citada neste artigo.
} 
Para ele, a instrução sexual deve ser dosada com parcimônia num programa que respeite ao mesmo tempo a idade e a curiosidade da criança sobre os enigmas da origem, da diferença de sexos, da fecundação, entre outros. Porto-Carrero se interessa em particular pelas experiências de Maria Montessori, de uma educação sem coerção. Mas, previne: "O método educativo não é de todo novo. É uma das normas da escola Montessori: mas a psicanálise vem dar base científica ao que fora adquirido empiricamente pela pedagogia" (PORTO-CARRERO, 1926/1929, p. 128). Mesmo que por vezes se inspire nos ensinamentos do pastor Pfister ou ainda do psicanalista austríaco August Aichhorn, especialista em delinqüência infantil e juvenil, suas referências vêm sobretudo das leituras da obras de Freud. Porém, ainda que em dia com a doutrina de seu mestre, da qual é capaz de mencionar sempre artigo mais recente, suas interpretações são marcadas pela primeira tópica, onde 0 apareIho psíquico é compreendido principalmente na distinção entre inconsciente, pré-consciente e consciente. 0 conceito do eu que designa a personalidade no seu conjunto, se inscreve no registro adaptativo, situado em relação à realidade externa.

Assim, inscrita no discurso médico da época, a psicanálise funciona como uma solução científica ideal para um projeto pedagógico moderno. Ela é recomendada "de preferência nas crianças nervosas, nas viciadas, nas que demonstrem peculiaridades de caracter, nas tímidas, nas arrogantes, nas rebeldes, nas mentirosas..." (PORTO-CARRERO, 1926/ 1929, p. 130). Para ele, a clínica psicanalítica pode "corrigir" todos esses "vícios" e "taras" pela técnica da associação de idéias e pela análise dos sonhos, dos lapsus, dos esquecimentos, assim como pela observação direta da criança, seus gestos, seus sorrisos, suspiros, sua respiração. Mas também através de "conselhos práticos" que são transmitidos aos pais, como, por exemplo, o da proibição da chupeta, 0 abandono da mamadeira, além das proibições envolvendo o hábito de os pais dormirem com os filhos na mesma cama ou então o hábito de roer as unhas. (PORTO-CARRERO, 1926/ 1929, p. 129). Tendo em vista o arsenal teórico e clínico do qual dispõe e os benefícios que ela traz, ele conclui: "A psicanálise pode ser desconhecida de todos os profissionais, mas ignorarem-na o médico e o mestre - é verdadeiro peccado" (PORTO-CARRERO, 1928 al 1929, p. 23).

Ao mesmo tempo que Porto-Carrero dá continuidade à sua campanha em prol da educação sexual nas escolas, em São Paulo, Franco da Rocha e o seu discípulo mais fiel à causa freudiana, o jovem médico Marcondes, também lançam 0 apelo. Em novembro de 1927, eles fundam a primeira instituição psicanalítica da América Latina, a Sociedade Brasileira de Psychanalyse (SBP). $\mathrm{Na}$ capital paulista o objetivo é o mesmo, ainda que exposto de uma forma 
mais moderada que o colega carioca: "fazer uma mais intensa propaganda dos princípios psycho-analyticos nas suas múltiplas applicações, devendo-se procurar interessar sobretudo a classe dos professores". ${ }^{7}$

Ao fundarem a SBP, os freudianos paulistas parecem dar provas de força e vitalidade. A Sociedade nasce graças à adesão de personalidades expressivas da elite intelectual local: médicos, escritores e membros ativos do movimento pedagógico local, como Raul Briquet e Lourenço Filho, que inclusive integram a primeira direção da entidade. ${ }^{8}$ Entretanto, uma vez lançado o movimento, é a Durval Marcondes - médico promissor em começo de carreira e praticamente sozinho - que cabe a responsabilidade de implantá-lo em São Paulo. Além disso, contrariamente a Porto-Carrero, ele não dispõe de boas entradas no também frágil universo psiquiátrico paulista e menos ainda no meio universitário. ${ }^{9}$ Seu campo de intervenção é praticamente reduzido ao seu trabalho no Serviço de Higiene e Educação Sanitária e na Liga Paulista de Higiene Mental (LPHM). A isso deve-se acrescentar que o presidente da SBP e seu mestre, ainda que gozando de todas as honras da Academia de Medicina, está aposentado e vive retirado na cidade litorânea de São Vicente. Quanto às ilustres personalidades que assinaram a ata de fundação da SBP, o engajamento se revela formal, e al guns chegam mesmo a retirar o apoio e rapidamente. Resultado: a instituição não sobrevive aos primeiros anos. ${ }^{10} \mathrm{~A}$ mesma situação se reproduz no Rio de Janeiro, ainda que o missionário Porto-Carrero conte com o apoio incondicional de Deodato de Moraes, autor do livro A psicanálisena educação, publicado prova-

\footnotetext{
${ }^{7}$ Extrato do discurso de fundação da Sociedade Brasileira de Psicanálise, pronunciado por Franco da Rocha e publicado no jornal Folha da Noite, de 27 de novembro de 1927.

${ }^{8}$ Entre as personalidades do movimento pedagógi co que assinam a ata de fundação da SBP, se encontram os futuros fundadores do movimento escolanovista, Lourenço Filho, Raul Briquet, Antonio Ferreira de Almeida Jr., Roldão Lopes de Barros e A. de Sampaio Dória. No que diz respeito a Raul Briquet, além da sua participação ativa no movimento pedagógico brasileiro, ele já é, nessa data, um brilhante professor de clínica obstétrica da Faculdade de Medicina de São Paulo. Quanto a Lourenço Filho, diplomado em direito, e antigo diretor e responsável pela reforma do ensino público do estado do Ceará em 1923, ele trabalha como professor de psicologia e pedagogia da Escola Normal de São Paulo desde 1925. Próximo da psicologia funcionalista de Claparède, seu nome consta entre as personal idades mais ilustres da Educação brasileira.

${ }^{9}$ Vale lembrar que, contrariamente ao Rio de Janeiro, nessa época a psiquiatria paulista estava praticamente restrita à prática asilar. 0 pouco que existia era controlado pelo psiquiatra A.C. Pacheco e Silva, também discípulo de Franco da Rocha, mas de formação organicista e próximo das teses da psicologia experimental.

${ }^{10}$ A pesar da vida curta, ela registra em seu passivo: al gumas tentativas frustradas de aproximação com o grupo carioca, a publicação de um primeiro e único número da Revista Brasileira de Psicanálise em junho de 1928, e algumas atividades programadas com o apoio da Associação Brasileira de Educação.
} 
velmente em $1927^{11}$ e para quem "a preocupação sexual é a causa dominante de todos os progressos em todos os ramos da atividade humana" (MORAES, [1927], p. 15).

Os sinais de recuo aparecem já no ano seguinte quando, juntos, eles organizam o primeiro "Curso de psychanalyse applicada à educação". ${ }^{12}$ Ao cabo de três meses de conferências, o balanço não traz o efeito esperado. Cerca de cinqüenta pessoas originárias da elite cultural, universitários, mas também mães desejosas de aprender a educar seus filhos assistiram às conferências. Mas para desalento dos organizadores os principais interessados, os pedagogos, foram os grandes ausentes.

Qual a razão do esfriamento das relações entre psicanalistas e educadores, desse afastamento, desse lugar vazio deixado pelos educadores? Sem esconder a frustração, Porto-Carrero formula al gumas hipóteses: "ou porque os dispensasse a cultura superior que possuem, ou porque os inibissem os preconceitos vulgarmente ligados à teoria sexual, ou porque não Ihes interessem o progresso da Educação nem a sorte dos pequenos brasileiros" (1928c/ 1929, p. 144).

As razões são provavelmente diversas, porém pouco exploradas pelos historiadores, quando não ignoradas. Arriscamos aqui a hipótese de que este vazio se produz entre 1928 e1930, e pode estar relacionado a dois fatores ao mesmo tempo distintos e complementares. 0 primeiro seria devido à preponderância entre os pedagogos de uma filiação a uma concepção de ordem psicossociológica da educação, próxima uma vez mais da escola francesa. Além disso, deve-se acrescentar o espaço de autonomia que a psicanálise rapidamente adquire enquanto discurso sobre a criança. U ma coisa é ser apresentada como disciplina auxiliar à prática médico-pedagógica, outra bem diferente é ser reivindicada como um saber mais amplo quando não essencial acerca da evolução do desenvolvimento mental da criança.

\footnotetext{
${ }^{11}$ Autor do primeiro livro de psi canálise aplicada à educação no Brasil, ex-professor de pedagogia e psicologia experimental da Escola Normal de São Paulo, Deodato de Moraes é, nessa época, membro do conselho diretor da ABE e inspetor escolar do Distrito Federal. Seu livro, prefaciado por Porto-Carrero, procura fazer um resumo das principais teses freudianas a partir de uma bibliografia em francês. Para tal, ele é dividido nos seguintes capítulos: Introdução, generalidades, libido; Evolução sexual; prazer e realidade. 0 Inconsciente de Freud; censura, fixação, regressão, recalque; Modalidades do compromisso; Sexualidade infantil; Teoria dos sonhos; Teoria dos símbolos; Da Sublimação em geral; e Dos Fatores da sublimação.

12 Composto de 23 conferências realizadas entre abril e julho de 1928, o curso tinha por objetivo oferecer uma visão geral dos principais conceitos e noções psicanalíticas de Freud e de seus discípulos e dissidentes, tais como o inconsciente, a sexualidade infantil, o sonho, a censura, a regressão, a sublimação, a castração, o recal que e o princípio de prazer. Além disso, duas conferências foram destinadas à sexualidade infantil, uma sobre educação sexual e psicanálise, e outra sobre as aplicações pedagógicas da analise dos sonhos.
} 
0 segundo fator estaria ligado aos efeitos negativos do freudismo difundido tanto como um saber pansexualista quanto como uma visão de mundo. Efeitos esses que ganham dimensões ainda mais importantes quando associados às transformações que se produzem nesse momento no país com o golpe de Estado de Getúlio Vargas, que coloca fim à República Velha e instaura, a partir de 1937, o Estado Novo. A nova orientação política de base totalitária que se implanta produz, entre outros, efeitos significativos nas concepções e normas familiares e morais ${ }^{13}$ Numa época de moralização dos costumes, é claro que essa psicanálise pansexualista, que se interessa pela sexualidade da criança estabelecendo para ela normas e valores morais, terá muita dificuldade para se impor e conseguir adeptos.

Um bom exemplo desse recuo é Renato Jardim. Entusiasta de primeira hora das teses freudianas, ele integra a comissão de redação da Revista Brasileira de Psicanálise, em 1928, ao mesmo tempo que é convidado a integrar o ciclo de conferências organizado por Porto-Carrero e Deodato Moraes. No entanto, para surpresa geral, no lugar de elogios à causa psicanalítica, ele apresenta suas primeiras reservas e provoca a polêmica. Mais tarde, suas críticas são retomadas e aprofundadas em Psychanalyse e educação, livro publicado provavelmente no começo 1931, ${ }^{14}$ e após uma série de conferências de Durval Marcondes na sede da ABE paulista, a convite de Raul Briquet, em 1930.15 O livro é lançado após o inquérito conduzido pelo jornal Diário da Noite, junto aos médicos, padres e educadores, entre maio e junho de 1930. Debate que divide as opiniões, provoca reações violentas e contribui para levar o movimento de implantação da psicanálise a um impasse.

Como já afirmamos antes, para boa parte dos médicos higienistas, convencidos da necessidade de se professar conhecimentos sobre a fisiologia das funções genésicas, a educação sexual serve para inculcar nos espíritos da juventude brasileira "a nobre significação da sua alta finalidade biológica e social" (GUERNER, 1930, p. 82). E como assinala ainda este autor - médico, membro do conselho executivo da LPHM e membro fundador da SBP — , nessa época ao se falar em sexualidade: "é, entre nós, quasi obrigatória, uma referência à psicanálise" (Idem, 1930, p. 84).

\footnotetext{
${ }^{13}$ É interessante lembrar aqui as teses de Daniel Pécault sobre as repercussões dessa política nas orientações de numerosos intelectuais, incitando-os a uma colaboração que conduz à militarização da vida política (PECAULT, 1989). Cabe assinalar, ainda, as teses de Eliana Dutra, que demonstram como, no campo do imaginário social, os discursos tanto de direita quanto de esquerda convergem para a construção de uma identidade nacional baseada em elementos total itários da vida psíquica (DUTRA, 1997).

${ }^{14}$ Esse livro foi publicado na coleção organizada por Lourenço Filho e intitulada Bibliotheca de Educação.

${ }^{15}$ Cf. BICUDO, 1948, p. 70.
} 
Com efeito, as "teses pansexualistas" são tomadas nesse inquérito como referencial para as mais diferentes personalidades consultadas. Independentemente das reações de reserva e de condenação que provocam, o fato é que, através da proposição de introduzir o ensino da educação sexual nas escolas pelo referencial psicanalítico, procura-se ao mesmo tempo estabelecer um campo preciso de ação para a psicanálise. Este é em todo caso o desejo de Durval Marcondes, manifesto nesse mesmo inquérito:

"Acho que, como primeira etapa na solução do problema da educação sexual, seria util interessar nos estudos psychanalyticos a nossa classe professoral. Foi o que procurei fazer com o curso que ha pouco tive occasião de realizar na Sociedade de Educação. U ma vez senhores das linhas geraes da psychologia freudiana, esses elementos poderiam seleccionar suas leituras, orientando-as para as obras de psychanalyse infantil e pedagógica, que hoje são innumeras. Tal aprendizado theorico seria - é claro - completado com o estudo directo da criança sob o ponto de vista psychanalytico. Só com esse trabalho preliminar de especialização é que se poderiam formar technicos que orientassem entre nós a organização da educação sexual, missão delicada na qual serão sempre poucos o saber e a prudência" (MARCONDES, 1930, p. 65-66).

Com essa afirmação, Marcondes atribui um outro estatuto à psicanálise, passando-a de coadjuvante a uma nova profissão, equivalente hoje à psicopedagogia. U m deslocamento que muito provavelmente contribuiu para o rompimento da aliança anunciada entre pedagogos e psicanalistas na ocasião da fundação da SBP em São Paulo.

Para melhor explicitar essa hipótese, tomaremos a Psychanalyse e educação de Renato Jardim como fio condutor, pois esse livro nos parece revelador tanto do recuo dos pedagogos como também do tipo de oposição que desde então vai se esboçar. Antes de tudo, é bom lembrar que Jardim é um leitor das obras psicanalíticas de Freud e de seus discípulos, em francês, assim como de diversos autores franceses, como Laforgue, Régis e em particular Hesnard. Igualmente, ele é bastante próximo das obras psicológicas de Ribot et Janet, entre outros.

Como a maior parte dos seus colegas, ele não se opõe à psicanálise, ao contrário, a reconhece como saber autônomo que emerge no campo da psicologia e que se inscreve no domínio da universalidade dos objetos do conhecimento. Como dissemos, as coisas se complicam quando a pedagogia passa para o domínio da psicanálise. Seu maior adversário é Porto-Carrero, para quem a psicanálise traz uma "base científica" a tudo aquilo que a pedagogia havia adquirido pelo "empirismo" (PORTO-CARRERO, 1926, p.128). Jardim considera que ao tomar para si a responsabilidade pela orientação da educa- 
ção, a psicanálise procura anular as aquisições empíricas trazidas pela psicologia experimental, sem contudo trazer nenhuma contribuição científica(JARDIM, s.d. p. 171).

Para justificar suas críticas, Jardim toma como ponto de apoio as reservas à expansão da psicanálise para outros domínios, emitidas pelo próprio Freud, em A história do movimento psicanalítico (1914) e por Jones em seu livro Da psicanálise, que aliás acabara de ser traduzido para o português por Raul Briquet. Naturalmente, também se inspira nos textos de Pfister. Mas, segundo ele, mesmo sendo a concepção mais elaborada no domínio da educação e trazendo conselhos benéficos, ela não constitui nem um material novo nem se inspira na psicanálise. E para justificar, ele afirma: "Aliás, o conceito de'recalcamento' - de cujo conhecimento faz o psychanalysta o clou de toda a questão educativa da criança - não é um conceito de Freud", para em seguida completar dizendo, "extende-a Pfister aos impulsos instinctivos em geral, não só ao sexual" (JARDIM, s.d., p. 176). ${ }^{16}$

Mais ainda, Jardim constata que falta à psicanálise uma visão sociológica, uma crítica social essencial à concepção pedagógica. Como bom número de pedagogos brasileiros, sua concepção pedagógica se inspira em Dewey, Durkheim e Spencer, que consideram a educação uma obra social realizada para a comunidade e pela coletividade, e cujo objetivo é preparar a criança para a vida.

A divergência é, portanto, clara, principalmente com Porto-Carrero, que considera a psicanálise como "um methodo que se desenvolveu como systema filosófico e invadiu a esphera inteira das sciencias do espirito" (PORTOCARRERO, 1928a/ 1929, p. 14). O autor parte da constatação de que os sofrimentos emocionais, esses complexos recalcados, esses tabus milenares herdados das raças que compõem o povo sul-americano, índio, negro, europeu, estão na base dos conflitos íntimos. Mas para esse adepto das teses raciais, na sua vertente "positiva" e tão em voga nesses anos 20, considerando que é impossível se desfazer da mistura das raças, a prevenção dos males deve ser feita desde a infância, "tendo como núcleo, uma educação norteada no sentido de evitar à criança os traumas emotivos que ordinariamente servem de base futura à perversão sexual e à neurose" (PORTO-CARRERO, 1928d/ 1929, p. 195). Ele vai mesmo mais longe; entusiasmado com a Revolução Russa e convencido das transformações que a psicanálise pode provocar no indivíduo, ele vê se esboçar na proposição freudiana um projeto de sociedade ideal, sem crime, sem censura, sem punição. Isso porque:

\footnotetext{
${ }^{16}$ Com efeito, Freud evoca pela primei ra vez o problema da educação em Três ensai os sobrea teoria da sexualidade (1905) mas, como assinala Chemouni, "para salientar o benefício que 0 adulto pode retirar das energias infantis não reprimidas, na medida em que oferecem material para processo cultural de sublimação". (CHEMOUNI, 1993, p. 504)
} 
"Reconstruída a sociedade sobre novas bases, conhecida a trama sexual dos impulsos, varridos os tabus millenares e architectada sobre os fundamentos da nova sciencia esse mundo ideal com que sonhou Freud no seu livro Die Zukunft einer Illusion, o crime deixará de existir." (PORTO-CARRERO, 1928e/ 1929, p. 186) ${ }^{17}$

Apesar da sua interpretação bastante particular da obra de Freud, em seu programa de "educação moral do brasileiro" há uma confrontação com a religião como sistema moral, ao qual ele opõe um modelo racional, e de uma certa forma "modernizador" como sugere RUSSO (1998). Assim, continua Porto-Carrero:

"Se os nossos tabus religiosos persistirem - e não viveremos sem elles - que nos sejam menos coercitivos dos impulsos que levam o homem não só e directamente à nobre reprodução da especie, mas tambem aos mais elevados designios sociaes." (PORTO-CARRERO, 1928d/ 1929, p. 196)

E levam Renato Jardim a assinalar que mais grave que a sua ausência de uma visão de mundo, a psicanálise, ao investir nos complexos da família pelo método de exploração do inconsciente, tem a intenção de expurgar e lavar a alma através de um "processo de exorcismo" que é perigoso, pessimista e que, continua, já conduziu muitos adultos ao suicídio (JARDIM, s.d., p. 183). 0 autor temia sobretudo que os professores, "nem sempre de aguçado espírito crítico" ( p. 184), abraçassem essa doutrina, que qualifica de "complicada", "obscura", "pessimista" além de "fanatisadora", quando não entrincheirada no "complexo sexual" da qual se inspirou e que "simboliza", e com esse cabedal teórico partam na "caçada em larga escala aos 'complexos' das crianças e dos adolescentes" (JARDIM, s.d., p. 183).

É justamente neste ponto que reencontramos nossa segunda hipótese, pois, efetivamente, para os educadores a problemática da educação sexual é espinhosa, envolvendo questões que extrapolam os limites do campo teórico para se alojar no embate político, mais precisamente na polêmica que nesse momento divide o movimento pedagógico em dois campos. De um lado, o movimento renovador que, apesar da diversidade de concepções, se define por uma escola laica, para todos, portanto pública e sem separação de sexos. De outro, as correntes conservadoras que sustentam um projeto de ensino privado, religioso e com separação de sexos, cuja bandeira de luta é a proposta de introdução do ensino religioso nas escolas.

${ }^{17}$ Cabe lembrar que 0 futuro de uma ilusão foi publicado em 1927, e que a primeira menção de Porto-Carrero sobre esse texto data de 20 de abril de 1928, no artigo intitulado "Psychanalyse: a sua História e o seu conceito" (1928a/ 1929, p.21), o que comprova a atualidade das suas leituras das obras freudianas. 
Convocados pelo governo a elaborarem propostas com vistas à reforma do sistema de educação, os dois campos sabem que devem negociar suas posições. Como assinala Romanelli, "A questão do ensino religioso poderia ser considerada uma questão de ordem secundária na evolução do sistema educacional brasileiro, se não fossem as polêmicas que suscitou e as lutas ideológicas em que se envolveu" (ROMANELLI, 1978, p. 143).

Falta ainda precisar em que medida a política de conciliação entre os dois campos, negociada pelo governo durante o decênio $1930,{ }^{18}$ não teria contribuído para o recuo dos pedagogos no apoio à psicanálise. Partindo do pressuposto de ROMANELLI (1978, p. 142), de que a expansão do ensino e a sua renovação permaneceram subordinadas ao jogo de forças entre os dois campos em disputa nas estruturas de poder, é o caso de se perguntar em que medida esse projeto da psicanálise, esse saber sobre a sexualidade infantil agora concretizado na proposta de ensino de educação sexual, não teria embaraçado os pedagogos progressistas, tornando-a difícil de ser sustentada tanto no interior da ABE quanto nos debates com os setores conservadores. Não seria estranho supor que esses pedagogos temessem ser acusados de professar uma doutrina, que como lembra Jardim, condena "a moral existente sem offerecer um conceito de moralidade que a suppra, seja este espiritualista ou seja outro" (JARDIM, s.d., p. 174). Em todo caso, a posição do antigo membro da comissão de redação da Revista Brasileira de Psicanálise parece clara: “Tenhamos a coragem de dizer: ' Não se el abora uma pedagogia psychanalysta. A educação não tem nada a esperar da Psychanalyse'" (JARDIM, s.d., p. 185).

0 fato é que a partir desse período, não apenas os pedagogos progressistas se distanciam, como também os psicanalistas se tornam alvo de diversos outros ataques de intelectuais, não necessariamente opositores da psicanálise.

Um bom exemplo é Alceu Amoroso Lima. Um dos principais ideólogos do pensamento autoritário, conservador e católico brasileiro, vez por outra, encontramos menções à teoria freudiana em suas crônicas literárias publicadas no quotidiano carioca 0 Jornal (LIMA, 1966). Mas suas críticas ganham forma mais elaborada em 1929, quando, sob o pseudônimo deTristão de Athayde, publica um opúsculo dedicado à análise filosófica do pensamento freudiano intitulado Freud (LIMA, 1929).

\footnotetext{
${ }^{18}$ No começo dos anos 30, o debate sobre a elaboração das diretivas para a educação nacional, propostas pelo governo, culminou na elaboração do M anifesto dos Pione ros da Escola Nova em 1932, reunindo as correntes progressistas que faziam oposi ção aos grupos conservadores e católicos a propósito da introdução do ensino religioso nas escolas públicas. A conciliação entre os dois campos se materializa nas duas Constituições brasileiras, na de 1934 e na de 1937 (ver ROMANELLI, 1978, p. 144-145).
} 
Para ele, Freud é "um Nietszche sem gênio". Enquanto o segundo via no homem uma criatura de força e de controle, cuja humanização se fazia pela vontade de ser forte face à sedução e humildade, um "super-homem" , o primeiro via apenas uma criatura de instintos, subordinada a toda espécie de influências, e cuja sublimação se faz pela utilização de todas as suas forças, um "inferhomem" (LIMA, 1929, p. 9). Esses dois autores, com Marx que impõe o "predomínio do homem sobre a natureza", seriam os representantes típicos do individualismo e do materialismo que dominam nossa época.

Mais para além da sua recriminação à crítica de Freud sobre a religião expressa em Totem e tabu (1912-1913), ele se mostra indignado mesmo é com o que chama de "animalisação" freudiana que subordina o homem à sexualidade infantil. Assim, afirma:

"Nenhum pensador contemporâneo ousou expor, com tanta audácia, as teorias mais repugnantes ao que havia de mais delicado, de mais intangível na alma dos homens: a pureza do sentimento filial e o respeito pela inocência infantil. Freud ousou." (LIMA, 1929, p. 33)

Mais moderado, ele retoma essa mesma temática com quase dez anos de intervalo afirmando que:

"o erro de Freud era apenas relativo [na medida em que] não são de todo inexatas suas observações. (... ) Erra apenas Freud quando nos fornece, dos instintos infantis, a imagem de um adulto em ponto pequeno, descobrindo uma antecipação sexual, onde existe apenas a permanência de vários instintos primitivos." (LIMA, 1938/ 1958, p. 23)

Vale salientar no entanto que, sua posição, longe de ser original, traduz a do Vaticano, que nessa época condena de maneira severa o freudismo, ao mesmo tempo que proclama a psicanálise como símbolo da degradação dos valores da sociedade ocidental e em particular da família cristã. Em conseqüência, a leitura das obras de Freud é desaconsel hada pelo clero.

Assim, chegamos ao começo do decênio 1930, após cerca de 15 anos de difusão do pensamento freudiano no Brasil, constatando que a estratégia estabelecida pelos primeiros psicanalistas que poderia ter representado uma primeira via de expansão da psicanálise se revelou desastrosa. Facilitada pela emergência do pensamento autoritário no país, é no campo da moral que finalmente se manifestam as resistências e os ataques mais violentos à psicanálise. Não raro ela é denunciada entre outros como "perigosa", "nefasta", " perniciosa" , ou ainda "falsa ciência do mundo subjetivo". Isso quando não é, ao contrá- 
rio, ironizada ou transformada em chacota. É o caso, por exemplo de Oswald de Andrade, quando o debate com Freud e em particular sobre a temática do pansexualismo se estende ao longo de sua obra. Nele, contudo, essa questão fica inteiramente desvestida de valor moral, e é Freud que se torna um moralista, um "defensor dos valores dessa sociedade", um burguês decadente. De seus escritos emerge um Freud que "se ressente dos resíduos vigentes da formação cristã-ocidental" (ANDRADE, 1950/ 1972, p. 125) e uma psicanálise como visão de mundo no lugar de uma proposição clínica.

Durval Marcondes é o primeiro a fazer um balanço negativo e a tirar lições desse fracasso. No comando do movimento psicanalítico paulista, ele muda a direção procurando evacuar do seu discurso o aspecto sexual da doutrina. Ao passo que no Rio de Janeiro, Porto-Carrero se lança, juntamente com um seleto grupo de médicos, num trabal ho de tradução das obras de Freud e uma intervenção mais reservada junto ao meio médico e universitário carioca, interrompida por sua morte prematura em 1938. Nessa cidade, o movimento psicanalítico só será retomado com força na década de 40, com a criação, em 1944, do Centro de Estudos Juliano Moreira, destinado a agrupar médicos interessados na psicanálise.

Mas nesse começo dos anos 30, é finalmente a Arthur Ramos que cabe apaziguar os ânimos e tentar temperar o debate com os pedagogos por meio da publicação, por sugestão de Afrânio Peixoto, do seu primeiro livro sobre o tema, intitulado Educação e psicanálise, em 1934. Partindo do princípio de que a Escola Nova e a psicanálise têm em comum o "respeito à personalidade da criança", e ao mesmo tempo considerando que "a repulsa em admitir a sexualidade infantil está na sua interpretação do ponto de vista do adulto", o autor procura desenvolver algumas das principais noções psicanalíticas passíveis de serem aplicadas à escola, com o objetivo de modelar e adaptar a personalidade do aluno (RAMOS, 1934). Cabe lembrar que Ramos é discípulo de Nina Rodrigues, de quem tenta recuperar a imagem, como fundador da psicopatologia no Brasil. Em breve, sua concepção da psicanálise vai se aproximar da vertente culturalista, pelo viés da antropologia e por influência do francês Roger Bastide.

No entanto, para o missionário Marcondes, trata-se de recentrar o domínio da psicanálise, buscando inscrevêla agora no meio médico e psiquiátrico. Os sinais dessa mudança estratégica do discurso se verificam tanto nas suas entrevistas na imprensa quanto em suas intervenções naAssociação Paulista de M edicina(APM) ${ }^{19}$

\footnotetext{
${ }^{19}$ A Associação Paulista de Medicina, fundada em setembro de 1931, foi o primeiro órgão importante de debate e difusão de trabal hos científicos de medicina de São Paulo. Marcondes figura entre os membros fundadores e mais ativos. Além de participar da primeira gestão da "Secção" de neuropsiquiatria como segundo secretário, ao lado do presidente EnroljasVampré e de James Ferraz Alvim, primeiro secretário.
} 
Mas, para simbolizar essa nova estratégia, nada melhor que a publicação de uma segunda edição do livro de Franco da Rocha, o mesmo que havia lançado a psicanálise em São Paulo dez anos antes, só que desta vez com o título A doutrina de Freud, em 1930.

Desde então, no discurso de Marcondes, a psicanálise aparece como uma "teoria das neuroses" e um método de investigação do inconsciente que rompe com a "velha psiquiatria organicista". Marcondes insiste sobretudo na importância da psicanálise para a compreensão da gênese psicológica das manifestações mentais mórbidas e sua ação no combate às doenças mentais, como a histeria, ao mesmo tempo que salienta, como seu mestre Franco da Rocha, que as manifestações graves, mais ligadas às condições orgânicas, não podem ser solucionadas pela psicanálise. Aliás, ele se queixa de seus colegas que só encaminham para ele pacientes apresentando um sintomatologia perversa, geralmente homossexuais, que segundo seu ponto de vista são os casos mais difíceis, quando não os menos recomendados. Em contrapartida, ele apresenta diversos casos tratados pelo método da associação de idéias e análise dos sonhos, em particular aqueles em que há intervenção do complexo familiar no mecanismo patogênico, o núcleo central de todas as psiconeuroses (MARCONDES, 1934/ 1935).

De modo geral, pode-se dizer que suas intervenções se caracterizam por uma leitura mais elaborada dos textos freudianos e um manejo mais sutil dos conceitos psicanalíticos adquiridos na clínica. Por outro lado, ainda que consiga aos poucos suavizar a dimensão sexual das suas interpretações, sua compreensão do aparelho psíquico, aqui já inscrita na Segunda tópica freudiana, é profundamente marcada pelas concepções higienistas da época, em particular as de correção dos "desvios da normalidade". 0 que faz a diferença é que a normalidade se estabelece, segundo ele, pelo equilíbrio entre as três instâncias: ego, id e super-ego, ao passo que os desvios se cristalizam pelos desajustes "entre o núcleo central da personalidade, o 'ego', e as outras partes funcionais do aparelho psíquico" (M ARCONDES, 1938/ 1939, p. 4). 0 método psicanalítico se mede então pela sua capacidade de reajustar e adaptar os indivíduos com desvios de comportamento, isto porque "proporciona os elementos mais valiosos para corrigir seus desvios, uma vez que estes não ultrapassem certos limites e decorram dentro de circunstâncias nitidamente funcionais" (MARCONDES, 1938/ 1938, p. 5). Ou seja, ele privilegia o registro do aparelho psíquico adaptativo do eu como instância central da personalidade.

Em seu discurso, a psicanálise se objetiva e se torna uma concepção puramente psicológica, em oposição à idéia de anomalia e de lesão física propagada pela psiquiatria organicista, sem que isso represente uma ruptura com essa disciplina. Ao contrário, as implicações, tanto biológicas quanto psicológicas, 
que delimitam os campos de intervenção de cada disciplina, se encontram ligadas por um mesmo discurso de verdade e um ol har sobre a etiologia social das doenças mentais, que é o da medicina social na sua vertente preventiva e profilática. Contudo, permanece a idéia de que é na criança que se deve agir. Ela é 0 alvo principal da psicanálise. Isso porque a infância constitui o momento particular da formação da personalidade do indivíduo e sua adaptação ao meio social; ela é mesmo, lembra Marcondes, o " momento estratégico da luta contra as psicopatias" (MARCONDES, 1946, p. 44).

Assim, para que a psicanálise pudesse se implantar, sobretudo em São Paulo, foi preciso antes vesti-la de pansexualista em versão local, higienista de base educativa, para em seguida, tempos de moralização exigem, desvesti-la, e finalmente revesti-la, agora com conhecimentos e técnicas capazes de "prevenir", "combater" e "curar" as anomalias que impedem a adaptação da criança ao seu meio social. ${ }^{20}$

Esse longo processo se concretiza em dezembro de 1938, quando, ao lado da formação dos primeiros analistas pelo divã, Marcondes inaugura, na Secção de Higiene Mental Escolar da Secretaria Estadual de Educação de São Paulo, a Clínica de Orientação Infantil e com ela a primeira experiência de psicoterapia infantil no Brasil. Com essa nova roupagem e essa prática inovadora no país, inaugura também uma nova fase da história da psicanálise no Brasil, a que vai permitir de fato a sua implantação e expansão.

Recebido em 19/ 2/ 2002. Aprovado em 3/ 4/ 2002.

\footnotetext{
${ }^{20}$ Antes de começar a obter os primei ros frutos do seu investimento na psicanálise, Marcondes amarga ainda algumas derrotas. Entre elas, a rejeição da sua proposição de introdução da disciplinana Faculdade de Medicina, no momento da criação da U niversidade de São Paulo, em 1934. Ou ainda na ocasião do concurso para a cadeira de psiquiatria em 1936, quando perde para o seu principal inimigo, como ele discípulo de Franco da Rocha, o psiquiatra organicista Antonio Carlos Pacheco eSi lva. A essas derrotas acrescentam-se ainda as tentativas frustradas de trazer psicanalistas estrangeiros afiliados à IPA. A formação dos primeiros analistas pelo divã começa somente em novembro de 1937, após a chegada da jovem psicanalista alemã, Adelheid Koch, fugindo do nazismo.
} 


\section{BIBLIOGRAFIA}

ANDRADE, O. de. (1950/ 1972) "A crise da filosofia messiânica", in Obras completas, 6. Do pau-brasil à antropofagia e às utopias, Rio de Janeiro, Civilização Brasileira, p. 75-138.

AUSTREGÉSILO, A. (1917/ 1946) "A cura dos nervos", in Obras completas, VI, Rio de Janeiro, Guanabara Koogan.

BICUDO, V. (1948) "Contribuição para a história do desenvolvimento da psicanálise em São Paulo", in Arquivos de Neuropsiquiatria, n. 1, v. VI, São Paulo, p. 69-72.

CHEMOUNI, J. (1993) "Psychanalyse \& éducation", in L'apport freudien. Élements pour une encyclopédie de la psychanalyse, KAU FMANN, P. (dir.), Paris, Bordas, p. 504-510.

DUTRA, E. (1997) 0 ardil totalitário: imaginário político no Brasil dos anos 30, Rio de Janeiro/ Belo Horizonte, UFRJ/ UFMG.

FRANCO DA ROCHA, F. (1920) 0 pansexualismo na doutrina de Freud, São Paulo, Typographia Brasil de Rothschild Cia.

GAGEI RO, A. M. (2001) “L'Histoire de la psychanalyse au Brésil et de la formation de la Société Psychanalytique de Porto Alegre (1963)", tese de doutorado, Paris, Universidade de Paris VII.

GUERNER, F. (1930) [Resposta de Fausto Guerner ao inquérito do jornal Diário da Noite], in Archivos Paulistas de Hygiene Mental, n. 5, v. III, São Paulo, LPHM, p. 82.

JARDIM, R.[s.d.] Psychanalyse e Educação, São Paulo, Melhoramentos.

LIMA, A.A. (1966) Estudos literários. 1 (1919-1925), Rio de Janeiro, Aguilar. (1929) Freud, Rio de Janeiro, Centro Dom Vital.

(1938/ 1958) "Idade, sexo e tempo (Três aspectos da psicologia humana)", in Obras completas, XXVII, 9. ed., Rio de Janeiro, Agir.

MARCONDES, D. ( 1935) "Os resultados do tratamento psychoanalytico"

[Trabalho apresentado na Secção de Medicina, em 20 de abril de 1934], in Revista da Associação Paulista de Medicina, n. 1, v. VI, São Paulo, APM, p. 21-28.

- (1939) Aspectos do aproveitamento prático da psicanálise [ Trabal ho apresentado no I Congresso Paulista de Psicologia, Neurologia, Psiquiatria, Endocrinologia, Identificação, Medicina Legal e Criminologia, em julho de1938], em Recife, Separata de Neurologia. . (1946) "Clínica de orientação infantil: suas finalidades e linhas gerais", in Noções gerais de higiene mental da criança, São Paulo, Martins, p. 43-48.

MEDEIROS DE ALBU QUERQUE, J. J. C. C. (1922) Graves e fúteis, Rio de Janeiro, Livraria Ed. Leite Ribeiro.

MORAES, D. ( 1927 [?]) A psicanálise na Educação, Rio de Janeiro, Mendonça, Machado e Cia.

NUNES, S. A. (1988) "Da medicina social à psicanálise", in Percursos na História da Psicanálise, Rio de Janeiro, Taurus, p. 61-122.

PÉCAU LT, D. (1989) Entre le peuple et la nation: les intellectuels et la politique au Brésil, Paris, Editions de la Maison des sciences de l'homme. 
PORTO-CARRERO, J .P. (1926/ 1929) "Educação e psychanalyse" [Conferência de vulgarização irradiada pelo Radio-Club do Rio de Janeiro], in Ensaios de Psychanalyse, Rio de Janeiro, Flores \& Mano, p. 125-131. . (1927a) "Em torno da mesa (Variações sobre o narcisismo)" [Oração no Círculo do Magistério Superior, Rio de Janeiro], p. 61-65. . (1927b) "O carácter do escolar, segundo a psychanalyse" [Tese apresentada na I Conferência Nacional de Educação em Curitiba], p. 41-59.

. (1928a/ 1929) "Psychanalyse: a história e o seu conceito", in Ensaios de psychanalyse, Rio de Janeiro, p.11-25.

. (1928b) "Bases da educação moral do brasilei ro" [Estudo apresentado na Seção de Moral e Cívica da ABE], p. 83-96.

(1928c) "O ponto de vista metapsychológico" [XXIII Conferência do Curso de Psicanálise Applicada à Educação], p. 143-155.

. (1928d) "Prophylaxia dos males da emoção" [Texto para o I Congresso Latino-americano de Neurologia, Psychiatria e Medicina Legal, em Buenos Aires], p. 187-196.

. (1928e) "O conceito psychanalytico de Pena" [Conferência realizada na Universidade de Minas Gerais], nov, p. 177-186.

RAM OS, A. (1934) Educação e psychanalyse, São Paulo, Cia Editora Nacional. ROMANELLI, O. O. (1978/ 1985) História da Educação no Brasil (1930-1975), Rio de Janeiro, Vozes, 7. ed.

ROU DINESCO, E. (1994) Histoire de la psychanalyse en France 1 (1885-1939), Paris, Fayard.

. PLON, M. (1997) Dictionnaire de la psychanalyse, Paris, Fayard.

ROXO, H. (1921) Manual de psychiatria, Rio de Janeiro, Francisco Alves. . (1934a) "Introdução", in Novidades em doenças mentais, Rio de Janeiro, Atlântida, p. 5-9.

. (1934b) "A eschizophrenia e os modernos tratamentos", in Novidades en doenças mentais, Rio de Janeiro, Atlântida, p. 10-39.

RUSSO, J. (1997) "Dize-me com quem andas... (A doutrina panseuxalista de Freud e a psiquiatria brasileira no início do século)", trabalho apresentado no XXI Encontro Anual da Anpocs, Caxambu (mimeo.).

. (1998) "Raça, psiquiatria e medicina-legal. Notas sobre a'préhistoria' da Psicanálise no Brasil", in H orizontesAntropológic cos, ano 4, n. 9, p. 85-103.

C. Lucia Montechi V. de Oliveira

Rua Piauí, 335/ 112

01241-000 São Paulo SP

luva@osite.com.br 